\title{
SCALE SUBSTANCE OF WOOL
}

\author{
By Walton B. Geiger ${ }^{1}$
}

\begin{abstract}
Earlier work at this Bureau has shown that wool that has been reduced with thioglycolic acid and then alkylated with ethyl bromide is attacked by pepsin in such a way that the scale material remains intact, whereas the interior of the fiber is completely dissolved. The composition of the scale material so obtained has now been studied. It has been found that it is essentially protein in chemical nature and, although it contains the same amino acids as the whole wool, the proportions of these in the two materials differ; thus, the whole wool used in this work contained 12.2 percent of cystine, 8.6 of arginine, 6.1 of tyrosine, and 9.5 of serine, whereas the scale material contained $20.3,4.8,3.3$, and 11.2 percent, respectively.
\end{abstract}

\section{CONTENTS}

I. Introduction

II. Experimental procedure _... 128

1. Reduction and alkylation

2. Treatment with pepsin

III. Results and discussion

IV. Conclusions . . _

V. References

\section{INTRODUCTION}

A wool fiber usually consists of three concentric regions: (1) a thin outer layer called the cuticle, usually about 1 to 2 microns thick and made up of overlapping scales, (2) the cortex, or main body, of the fiber, and (3) a central pith, or medulla $[1]^{2}$ In fine wool, the last is generally lacking. The cuticle has been suggested to have a protective function, since it is mechanically tougher and chemically more stable than the rest of the fiber $[1,2,3,4]$. It has been suggested also that the ability of wool fibers to felt is at least partially dependent on these scales (literature reviewed in 「51).

Little is known about the composition of the scales, since ready means for separating them from the rest of the fiber have not been available. From experiments involving partial hydrolysis of wool with hydrochloric acid, Trotman, Trotman, and Sutton [4] concluded that the scales were richer in sulfur than the cortex. Also, a number of investigators $[6,7,8,9]$ have concluded from color tests made under the microscope that the cuticle contains little or no tyrosine.

Recent work at this Bureau [10] has shown that wools chemically modified by reduction with thioglycolic acid, followed by alkylation

1 Research Associate at the National Bureau of Standards, representing the Textile Foundation

2 Figures in brackets indicate the literature references at the end of this paper. 
with methyl iodide or ethyl bromide, are attacked by pepsin, and that the pepsin digests the inner portions of the fiber, leaving the cuticle intact. The present paper reports some analytical results on the composition of scale material obtained in this way.

\section{EXPERIMENTAL PROCEDURE}

\section{REDUCTION AND ALKYLATION}

The reduction and alkylation were carried out by methods similar to those previously described [11, 12]. A $140-\mathrm{g}$ sample of wool was reduced for $24 \mathrm{hr}$ at $35^{\circ} \mathrm{C}$ with $4,000 \mathrm{ml}$ of a $0.2 \mathrm{~N}$ solution of sodium thioglycolate brought to $\mathrm{pH} 8.0$ with potassium hydroxide. The yarn was then removed from the solution, washed thoroughly with water, and alkylated by treating it for $2 \mathrm{hr}$ with $2,000 \mathrm{ml}$ of a $0.1 \mathrm{~N}$ phosphate buffer solution at $\mathrm{pH} 8.0$, in which had been suspended $25 \mathrm{~g}$ of ethyl bromide. After again washing the wool with water, the process es of reduction and alkylation were repeated. The product was again washed, dried, and finally comminuted in a Wiley mill.

\section{TREATMENT WITH PEPSIN}

The chemically modified wool was suspended in $3,000 \mathrm{ml}$ of a 0.2 $M$ solution of potassium chloride, which was adjusted to $\mathrm{pH} 1.1$ by the addition of hydrochloric acid, and which contained $1.0 \mathrm{~g}$ of pepsin. ${ }^{3}$ The suspension was kept at $35^{\circ} \mathrm{C}$ and slowly stirred for 5 days. After this length of time, examination under the microscope indicated that the residue consisted almost entirely of scales, and that all the cortical material had been dissolved.

The scale material was separated by centrifuging and was washed several times with a 5-percent solution of potassium chloride and several times with distilled water. The material then was dried by washing it with alcohol and then with ether, and the final drying was done over concentrated sulfuric acid in a vacuum desiccator. The dried product formed a light-brown, horny mass weighing $3.283 \mathrm{~g}$, representing about 2.3 percent of the weight of the wool.

\section{RESULTS AND DISCUSSION}

Preliminary qualitative tests of the scale material indicated that it was composed largely of protein. It gave positive xanthroproteic [13] and biuret [13] reactions. Moreover, the Millon [13] reaction, given by proteins containing tyrosine or tryptophane, the alkaliplumbite [14] reaction, given by those containing sulfur, and the Sakaguchi [13] reaction, given by those containing arginine, were all positive. The Ehrlich [13] reaction for amino sugars was negative. Only a faintly positive test for carbohydrate was obtained when the Molisch [13] test was applied. No carbohydrate could be detected by using Fehling's solution or by Beek's [15] method. A test for bound lipid by the method of Anderson [16] showed that the material contained 2.7 percent of lipid. On ignition [17], 4.13 percent of ash was found to be present.

Determination of nitrogen by the micro-Kjeldahl procedure of Clarke [18] gave 13.53 percent, somewhat less than the amount usually

${ }^{3}$ From Fairchild Bros. \& Foster, New York, N. Y. 
found in proteins, but correction for ash, lipid, and the ethyl groups introduced chemically increased this to 15.17 percent, a value just slightly lower than that given by wool (table 1). This difference seems largely due to the smaller arginine content of the scale material, which contained only about half as much arginine (4.8 percent) as whole wool (8.6 percent). Arginine is the richest in nitrogen of the amino acids. The scale material contained 5.42 percent of sulfur [20], which is considerably more than that in untreated wool $(3.50$ percent).

TABLE 1.-Composition of untreated wool and of wool scales

\begin{tabular}{|c|c|c|c|}
\hline \multirow{2}{*}{ Constituent } & \multirow{2}{*}{$\begin{array}{c}\text { Untreated } \\
\text { wool }\end{array}$} & \multicolumn{2}{|c|}{ Wool scales } \\
\hline & & Found & $\begin{array}{c}\text { Corrected } \\
\text { value a }\end{array}$ \\
\hline Sulfur & 3.50 & 4.83 & 5.42 \\
\hline Cystine & 12.2 & b18. 1 & b20.3 \\
\hline Nitrogen. & 16. 67 & 13.53 & 15. 17 \\
\hline Arginine. & 8.6 & 4. 3 & 4.8 \\
\hline Tyrosine & 6.1 & 3.0 & 3.3 \\
\hline Serine & 9.5 & 9.9 & 11. 2 \\
\hline Ethyl groups ... & 0.0 & 4. 0 & n. \\
\hline Ash & .2 & 4. 1 & (n) \\
\hline Lipid & $-\ldots$ & 2.7 & - n \\
\hline
\end{tabular}

a Corrected for the presence of ethyl groups, ash, and bound lipid, as described in the text.

b Calculated from the sulfur content.

The sulfur in the scale material probably was largely in the form of S-ethyl cysteine, since the determination of the ethyl groups [21] showed that 4.0 percent was present, a result which indicates that 1.51 millimoles of sulfur and 1.38 millimoles of ethyl groups were present per gram of scale material. This S-ethyl cysteine had doubtless been formed from cystine by the reduction and alkylation processes used in preparing the material.

Determination of the tyrosine in the scale material [22] showed that it contained only about half as much (2.97 percent) as wool (6.10 percent). Analysis by the method of Nicolet and Shinn [23] showed that the scale material contained about the same amount of serine as wool.

\section{CONCLUSIONS}

Analytical studies of the cuticle of wool and of whole wool fibers show that although both contain the same amino acids, the proportions of these in the two materials differ. The presence of larger amounts of sulfur presumably means that the protein of the scales contains more sulfur cross-links between its peptide chains than do the more digestible proteins of the cortex. Nevertheless, even when the sulfur cross-links have been broken as in the present product, the material is not digested by enzymes. Moreover, the scale material was found to be more stable toward alkali than wool that had been reduced and alkylated in the same way, since the alkali-solubility [24] of the scale material was found to be only 42 percent and that of the treated wool 85 percent.

Two possible explanations have been advanced to account for the difference in behavior of the cuticle and the cortex of wool. Speakman, and also Rudall, have suggested that, since the cortex of wool 
fibers is attacked more rapidly by sodium sulfide than are the scales, cross-links other than those involving sulfur may be present. This hypothesis is supported by the results of the present work, although direct proof of the existence and nature of such cross-links is still lacking. An alternative explanation might be sought in the recent demonstration by Hock and McMurdie [25], with the electronmicroscope, that the cuticle and cortex differ widely in physical organization.

\section{REFERENCES}

[1] C. W. Hock, R. C. Ramsay, and M. Harris, J. Research NBS 27, 181 (1941) RP1412.

[2] K. M. Rudall, Proc. Leeds Phil. Lit. Soc., Sci. Sec. IV, Pt. I, 13 (July 1941).

[3] J. B. Speakman, J. Soc. Chem. Ind. 50T, 1 (1931).

[4] S. R. Trotman, E. R. Trotman, and R. W. Sutton, J. Soc. Chem. Ind. 45T, 20 (1926).

[5] S. G. Barker, Wool Quality (His Majesty's Stationery Office, London, 1931).

[6] C. Kronacher and G. Lodemann, Technik der Harr- und Wooluntersuchungen (Urban \& Schwarzberg, Berlin, 1930)

[7] J. G. Bekker and A. T. King, Biochem. J. 25, 1077 (1931).

[8] R. Haller, Milliand Textilber. 18, 5 (1937).

[9] Unna and Golodety, quoted by H. Mark, Beitrage zur Kentnis der Wolle, Einzedarstellung aus dem Kaiser-Wilhelm-Institut der Faserstoffchemie 1 (1925).

[10] W. B. Geiger, W. I. Patterson, L. R. Mizell, and M. Harris, J. Research NBS 27, 459 (1941) RP1433.

[11] W. I. Patterson, W. B. Geiger, L. R. Mizell, and M. Harris, J. Research NBS 2\%, 89 (1941) RP1405.

[12] W. B. Geiger, F. F. Kobayashi, and M. Harris, Ind. Eng. Chem. 34, 1398; J. Research NBS $\mathbf{2 9 ,} 381$ (1942) RP1506.

[13] P. B. Hawk and O. Bergeim, Practical Physiological Chemistry (Blakiston, Philadelphia, Pa., 1937).

[14] H. Zahnd and H. T. Clarke, J. Biol. Chem. 102, 271 (1933).

[15] J. Beek, J. Research NBS 27, 507 (1941) RP1438.

[16] W. B. Geiger and R. J. Anderson, J. Biol. Chem. 129, 519 (1939).

[17] Assoc. Official Agr. Chem., Official and Tentative Methods of Analysis 116 (1925).

[18] E. P. Clarke, J. Assoc. Official Agr. Chem. 24, 641 (1941).

[19] L. E. Thomas, J. K. Ingalls, and J. M. Luck, J. Biol. Chem. 129, 263 (1939).

[20] A. Elek and D. A. Hill, J. Am. Chem. Soc. 55, 3479 (1933).

[21] A. Elek, Ind. Eng. Chem., Anal. Ed. 11, 174 (1939).

[22] J. H. W. Lugg, Biochem. J. 31, 1422 (1937).

[23] B. H. Nicolet and L. A. Shinn, J. Biol. Chem. 139, 687 (1941).

[24] M. Harris and A. L. Smith, J. Research NBS 17, 577 (1936) RP928.

[25] C. W. Hock and H. F. McMurdie, J. Research NBS 31, 229 (1943) RP1561.

Washington, December 31, 1943. 
NATIONAL BUREAU OF STANDARDS, WASHINGTON 25, D. C.

Send me the Mathematical Tables marked $\mathrm{X}$ below. I enclose remittance ${ }^{1}$ to cover the cost.

\begin{tabular}{|c|c|c|c|c|}
\hline Mark X & Title of publication & $\begin{array}{l}\text { United States and } \\
\text { its possessions, } \\
\text { and countries ex } \\
\text { tending franking } \\
\text { privilege } \\
\end{array}$ & $\begin{array}{l}\text { Other } \\
\text { countries }\end{array}$ & Amount enclosed \\
\hline & 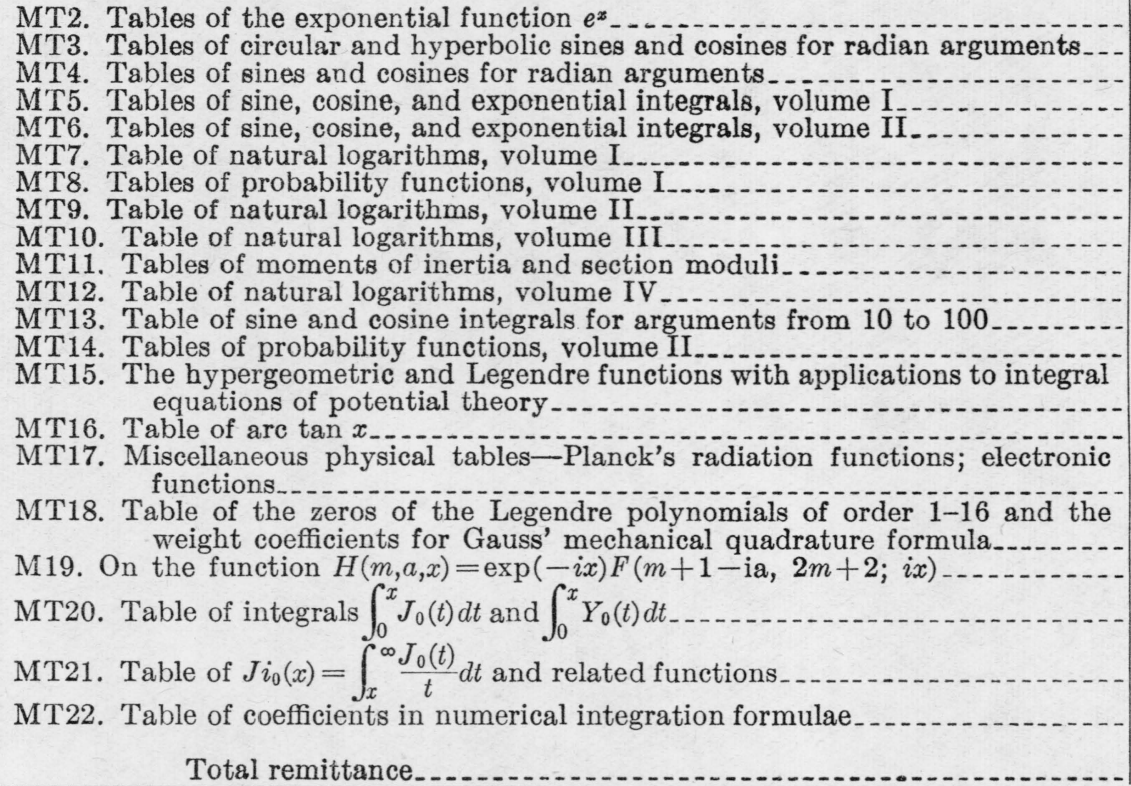 & $\begin{array}{l}2.00 \\
2.00 \\
2.00 \\
2.00 \\
2.00 \\
2.00 \\
2.00 \\
2.00 \\
2.00 \\
2.00 \\
2.00 \\
2.00 \\
2.00 \\
2.00 \\
2.00 \\
1.50 \\
.25 \\
.25 \\
.25 \\
.25 \\
.25\end{array}$ & $\begin{array}{r}\$ 2.50 \\
2.50 \\
2.50 \\
2.50 \\
2.50 \\
2.50 \\
2.50 \\
2.50 \\
2.50 \\
2.50 \\
2.50 \\
2.50 \\
2.50 \\
2.50 \\
2.50 \\
1.75 \\
.30 \\
.30 \\
.30 \\
.30 \\
.30\end{array}$ & \begin{tabular}{c}
-1. \\
\hdashline \\
\hdashline \\
\\
\hdashline \\
\end{tabular} \\
\hline
\end{tabular}

Send to

Number and Street 


\section{MATHEMATICAL TABLES}

Attention is invited to a series of publications prepared by the Project for the Computation of Mathematical Tables conducted by the Federal Works Agency, Work Projects Administration for the City of New York, under the sponsorship of the National Bureau of Standards. The tables which have been made available through the National Bureau of Standards are listed below.

There is included in this list a publication on the hypergeometric and Legendre functions (MT15), prepared by the Bureau.

MT1. Table of the First Ten Powers of the Integrrs From 1 to 1000:

(1938) VIII+80 pages; heavy paper cover. Out of print.

MT2. TABlis of the Exponential Function $e^{x}$ :

The ranges and intervals of the argument and the number of decimal places in the entries are given below:

$\begin{array}{lcc}\text { Range of } x & \text { Interval of } x & \text { Decimals given } \\ -2.5000 \text { to } 1.0000 & 0.0001 & 18 \\ 1.0000 \text { to } 2.5000 & .0001 & 15 \\ 2.500 \text { to } 5.000 & .001 & 15 \\ 5.00 \text { to } 10.00 & .01 & 12\end{array}$

(1939) XV+535 pages; bound in buckram, $\$ 2.00$.

MT3. Tables of Circular and Hyperbolic Sines and Cosings for Radian Arguments:

Contains 9 decimal place values of $\sin x, \cos x, \sinh x$ and $\cosh x$ for $x$ (in radians) ranging from

0 to 2 at intervals of 0.0001 .

(1939) XVII+ 405 pages; bound in buckram, $\$ 2.00$.

MT4. Tables of Sines and Cosines for Radian Arguments:

Contains 8 decimal place values of sines and cosines for radian arguments ranging from 0 to 25 at intervals of 0.001 .

(1940) XXIX + 275 pages; bound in buckram, $\$ 2.00$.

MT5. Tables of Sine, Cosine, and Exponential Integrals, Volume I:

Values of these functions to 9 places of decimals from 0 to 2 at intervals of 0.0001 .

(1940) XXVI+444 pages; bound in buckram, $\$ 2.00$.

MT6. Tables of Sine, Cosine, and Exponential Integrals, Volume II:

Values of these functions to 9,10 , or 11 significant figures from 0 to 10 at intervals of 0.001 with auxiliary tables.

(1940) XXXVII + 225 pages; bound in buckram, $\$ 2.00$.

MT7. Table of Natural Logarithms, Volume I:

Logarithms of the integers from 1 to 50,000 to 16 places of decimals.

(1941) XVIII+501 pages; bound in buckram, $\$ 2.00$.

MT8. Tables of Probability Functions, Volume I:

Values of these functions to 15 places of decimals from 0 to 1 at intervals of 0.0001 and from 1 to 5.6 at intervals of 0.001 .

(1941) XXVIII+302 pages; bound in buckram, $\$ 2.00$.

MT9. Table of Natural Logarithms, Volume II:

Logarithms of the integers from 50,000 to 100,000 to 16 places of decimals.

(1941) XVIII + 501 pages; bound in buckram, $\$ 2.00$.

MT10. Table of Natural Logarithms, Volume III:

Logarithms of the decimal numbers from 0.0001 to 5.0000 , to 16 places of decimals.

(1941) XVIII+ 501 pages; bound in buckram, $\$ 2.00$.

MT11. Tables of the Moments of Inertia and Section Moduli of Ordinary Angles, Channels, and Bulb Angles With Certain Plate Combinations:

(1941) XIII+197 pages; bound in green cloth, \$2.00.

[Continued on p. 4 of cover] 
MT12. Table of Natural Logarithms, Volume IV:

Logarithms of the decimal numbers from 5.0000 to 10.0000 , to 16 places of decimals. (1941) XXII+ 506 pages; bound in buckram, $\$ 2.00$.

MT13. Table of Sine and Cosine Integrals for Arguments from 10 to 100:

(1942) XXXII + 185 pages; bound in buckram, $\$ 2.00$.

MT14. Tables of Probability Functions, Volume II:

Values of these functions to 15 places of decimals from 0 to 1 at intervals of 0.0001 and from 1 to 7.8 at intervals of 0.001 .

(1942) XXI+344 pages; bound in buckram, $\$ 2.00$.

MT15. The hypergeometric and Legendre functions with applications to integral equations of potential theory. By Chester Snow, National Bureau of Standards. Reproduced from original handwritten manuscript.

(1942) VII + 319 pages; bound in heavy paper cover, $\$ 2.00$.

MT16. TABLE OF ARc TAN ${ }^{x}$ :

Table of inverse tangents for positive values of the angle in radians. Second central differences are included for all entries.

$$
x=\llbracket 0(.001) 7(.01) 50(.1) 300(1) 2000(10) 10,000 ; 12 D \rrbracket
$$

(1942) XXV+169 pages; bound in buckram, $\$ 2.00$.

MT17. Miscellaneous Physical Tables:

Planck's radiation functions (Originally published in the Journal of the Optical Society of America, February 1940); and

Electronic functions.

(1941) VII+58 pages; bound in buckram, $\$ 1.50$.

MT18. Table of the Zeros of the Legendre Polynomials of Order 1-16 and the Weight Coefficients for Gauss' Mechanical Quadrature Formula:

(Reprinted from Bul. Amer. Mathematical Society, October 1942.)

5 pages with cover. 25 cents.

MT19. On the Function $H(m, a, x)=\exp (-i x) F(m+1-i a, 2 m+2 ; i x)$; with table of the confluent hypergeometric function and its first derivative.

(Reprinted from Journal of Mathematics and Physics, December 1942.) 20 pages, with cover. 25 cents.

MT20. Table of Integrals $\int_{0}^{x} J_{0}(t) d t$ and $\int_{0}^{x} Y_{0}(t) d t$ :

Values of the two integrals are given for $x=0(.01) 10$ to 10 decimal places. (Reprinted from Journal of Mathematics and Physics, May 1943.) 12 pages, with cover, 25 cents.

MT21. Table of $J i_{0}(x)=\int_{x}^{\infty} \frac{J_{0}(t)}{t} d t$ and Related Functions:

Table I: $J i_{0}(x)$ to 10 decimal places and $F(x)=J i_{0}(x)+\log _{e} 1 / 2 x$ to 12 decimal places for $x=0(.1) 3$ with even central differences of $F(x)$.

Table II: $J i_{0}(x)$ to 10 decimal places, for $x=3(.1) 10(1) 22$ with even central differences up to $x=100$.

Table III: "Reduced" derivatives of $F(x)$ for $x=10(1) 21$ and $n=0(1) 13$, to 12 decimal places.

(Reprinted from Journal of Mathematics and Physics, June 1943.) 7 pages, with cover, 25 cents. Eents.

MT22. Table of Coefficients in Numerical Integration Formula:

The values of $B_{n}{ }^{(n)}(1) / n !$ and $B_{n}^{(n)} / n !$, where $B_{n}^{(n)}(1)$ denotes the $n^{\text {th }}$ Bernoulli polynomial of the $n^{\text {th }}$ order for $x=1$ and $B_{n}^{(n)}$ denotes the $n^{\text {th }}$ Bernoulli number of the $n^{\text {th }}$ order, were como puted for $n=1,2, \ldots 20$. The quantities $B_{n}{ }^{(n)}(1) / n !$ are required in the Laplace formula of numerical integration employing forward differences, as well as in the Gregory formula. The quantities $B_{n}^{(n)} / n$ ! are used in the Laplace formula employing backward differences.

(Reprinted from Journal of Mathematics and Physics, June 1943.) 2 pages, with cover, 25 cents.

Payment is required in advance. Make remittance payable to the "National Bureau of Standards," and send with order, using the blank form facing page 3 of the cover.

A mailing list is maintained for those who desire to receive announcements regarding new tables as they become available. 